\title{
The effectiveness of the intercultural language communicative teaching model for EFL learners
}

Thao Quoc Tran ${ }^{1 *}$ and Tham My Duong ${ }^{2}$

\author{
* Correspondence: \\ tq.thao@hutech.edu.vn \\ ${ }^{1}$ Faculty of English Language, Ho \\ Chi Minh City University of \\ Technology, 475A Dien Bien Phu \\ Street, Ward 25, Binh Thanh District, \\ Ho Chi Minh City 700000, Vietnam \\ Full list of author information is \\ available at the end of the article
}

\begin{abstract}
Over the past years, there has been a growing interest in intercultural communicative competence (ICC) in English language education. However, not all English language educators in the Vietnamese context and other similar contexts are well aware of intercultural language teaching since there lacks instructional design models to integrate intercultural content into English language classes. This project, therefore, aims to test the effectiveness of a developed intercultural communicative language teaching (ICLT) model. It involved forty-seven EFL learners learning General English at a foreign language center in Ho Chi Minh City, Vietnam. Three research instruments, namely language test, intercultural competence test and semi-structured group interview were employed to garner data. The findings revealed that after a thirteen week training course, EFL learners' language competence and intercultural competence had similar patterns of improvement. This project, thus, implies that the ICLT model is effective in facilitating EFL learners' ICC development, and it can be applied in other similar EFL contexts.

Keywords: Intercultural communicative language teaching (ICLT), Intercultural communicative competence (ICC), EFL learners, Model, Vietnamese context
\end{abstract}

\section{Introduction}

In the current context of globalisation, English as an international language, lingua franca, and a global language (e.g., Tavakoli, Shirinbakhsh, \& Rezazadeh, 2012) is used as a means of communication in multicultural contexts. Additionally, in order to interact with people of different cultural backgrounds effectively and appropriately, one needs to be intercullturally communicative competent. Accordingly, the issue of developing intercultural communicative competence (ICC) to ESL/EFL learners has been identified as one of the ultimate goals in the field of English language education (e.g., Byram, 1997; Deardoff, 2009; Fantini, 2000; Lázár et al., 2007) in an attempt to present learners with cultural differences which help learners to be interculturally aware of their own culture and the presence of otherness as well as to appreciate and respect them. Moreover, English language education should equip learners with the knowledge of intercultural communication and the ability to use it effectively in order to bridge cultural differences and achieve more harmonious, productive relations (Samovar, Porter, \& McDaniel, 2012).

(c) The Author(s). 2018 Open Access This article is distributed under the terms of the Creative Commons Attribution 4.0 International License (http://creativecommons.org/licenses/by/4.0/), which permits unrestricted use, distribution, and reproduction in any medium, provided you give appropriate credit to the original author(s) and the source, provide a link to the Creative Commons license, and indicate if changes were made. 
Nevertheless, it is not always seen that the role of culture as well as intercultural communication in English language education is well acknowledged. Gonen and Saglam (2012) point out that "teachers in different classrooms in different parts of the world still ignore the importance of teaching culture as a part of language study" (p. 26). That is, teachers endeavor to promote only their learners' language proficiency instead of endowing them with ICC in order to function effectively and appropriately in multicultural situations. The reasons behind teachers' ignorance of inclusion of culture and intercultural communication in English language education are that teachers are "more interested in practical aspects of communication" (Onalan, 2005, p. 217); teachers feel they do not have enough time to talk about cultural elements in their teaching practices due to the demanding curriculum (e.g., Gonen \& Saglam, 2012; Hong, 2008); teachers do not know how to incorporate culture and intercultural communication in the language classroom since they lack adequate training on how to incorporate culture in their teaching practices as well as how to measure learners' intercultural competence (IC) and changes in their attitudes as a result of culture teaching (Gonen \& Saglam, 2012); and most teachers have limited knowledge about intercultural communication (Sercu, 2005).

Given the fact that the ICC is one of the key competences in the twenty-first century, so it is agreed that one of the ultimate goals in language training programs is to educate learners to become intercultural speakers who can deal with linguistic and cultural complexity and take part in multicultural situations (e.g., Deardoff, 2009; Jæger, 2001). Nevertheless, in the reality of English language education in Vietnam context, most of the English language training programs lack the integration of cultural content into their curricula, and English language users are, to some extent, incapable of using English appropriately and effectively when communicating with others from different linguistic and cultural backgrounds due to lack of awareness of cultural difference. It is, hence, imperative that developing ICC to EFL/ESL learners should be taken into serious consideration in English language training programs so as to help English learners become intercultural speakers who can function effectively and appropriately in the twenty-first century. This project aims to explore the effectiveness of utilising the intercultural communicative language teaching (ICLT) model in enhancing EFL learners' ICC, and it endeavors to address the research question as follows:

To what extent does EFL learners' ICC (language competence and intercultural competence) develop using the ICLT model?

\section{Literature review}

It is seen that the concept of ICC is variously defined by different scholars (e.g., Bennett \& Bennett, 2004; Byram, 1997; Fantini, 2001; Sinicrope et al., 2007), resulting in the confusion in addressing the same issue. In this project, ICC can be understood as the ability which enables one to effectively and appropriately interact in a language other than one's native language with others from different linguistic and cultural backgrounds. It consists of language competence (linguistic, sociolinguistic, and discourse competence) and intercultural competence (attitudes, knowledge, skills, and awareness) that help one to be able to successfully integrate in a multicultural society (adapted from Bennett \& Bennett, 2004; Byram, 1997; Fantini, 2001; Sinicrope et al., 2007).

From different views on ICC, it is seen that various models of ICC have been proposed to address many aspects of ICC, e.g., model of ICC (Byram, 1997); IC model 
(Fantini, 2000); pyramid model of IC (Deardorff, 2006). Byram's (1997) model of ICC is one of the most comprehensive frameworks to develop as well as evaluate learners' ICC in different contexts. In his ICC model, Byram (1997) points out that IC, which relates to other competences, namely linguistic competence, sociolinguistic competence and discourse competence, consists of five elements such as attitudes, knowledge, skills of interpreting and relating, skills of discovery and interaction, and critical cultural awareness/political education. Based upon this model, he formulates specific educational objectives which are designed for language and culture learning and serve as guiding criteria to develop and assess learners' IC in the foreign language class. Those educational objectives are specific and detailed, but they do not specify the different levels of IC to be obtained at different stages through the process of education since he argues that establishing levels is quite problematic for the attitude factor.

In respect of the Fantini's (2000) IC model which includes awareness, attitudes, skills, and knowledge, this IC model is likely to overlap with Byram's (1997) intercultural elements. Although the IC model does not include explicitly the element of language in the IC model, Fantini (1997) argues that proficiency in the host language plays an important part in enhancing one's IC. He adds that language education should focus more on intercultural aspects so that learners can develop "awareness, attitudes, skills, and knowledge that will make [them] better participants on a local and global level, able to understand and to empathize with others in new ways" (Fantini, 1997, pp. 13-14). In another aspect, Fantini (2000) explains that awareness which refers to self-awareness and reflection leads "deeper cognition, skills, and attitudes just as it is also enhanced by their development" (p. 29). In other words, awareness helps to develop other components of IC while it simultaneously benefits from their development. Furthermore, he points out that the development of IC is an on-going and lifelong process inasmuch as one is always in the process of 'becoming' and is never completely interculturally competent. He emphasizes that although one may develop and expand one's competencies, new challenges always appear, and a good condition for one to develop one's IC is the contact and experience with people of other languages and cultures in a positive setting.

Regarding the Deardorff's (2006) pyramid model of IC which is a research-based one, the pyramid model of IC has two other different elements of internal outcomes and external outcomes apart from the three elements of attitudes, knowledge, and skills as in Byram's (1997) and Fantini's (2000) models. All of these five elements are arranged in levels of the pyramid lower levels of which are the basis to enhance the higher ones. However, Deardorff (2006) develops another way to organize and display the data in the process model of IC, which contains the same elements as her pyramid model of IC. This process model of IC describes the complexity of acquiring IC from "attitudes and/or attitudes and skills/knowledge directly to the external outcome, but the degree of appropriateness and effectiveness of the outcome may not be nearly as high as when the entire cycle is completed and begins again" (ibid., p. 257).

There have been different studies which attempt to include intercultural content into language education. It is noticed that the most common focus of study is the application of information and communications technology (ICT) such as computer, the Internet, video and other technologies to promote the acquisition of IC/ICC (e.g., Garretts-Rucks, 2010; O'Neil, 2008). Other three common focuses of study are the 
use of new approaches in IC/ICC development (e.g., Gómez, 2012; Nakano et al., 2011), the contexts of ICC promotion (e.g., Pierson, 2010; Ottoson, 2013), and the characteristics / difficulties / challenges / factors in intercultural communication (e.g., Alexandru, 2012; Moloney, 2007). However, no research has been reported conducting an action research to develop EFL learners' ICC by applying a specific ICLT model in the Vietnamese EFL context. This study is, therefore, hoped to fill up such a gap in the context of Vietnam.

\section{Methods}

\section{Intercultural communicative language teaching (ICLT) model}

Prior to the experiment, an ICLT model was developed to facilitate EFL learners' ICC development.

The ICLT model is an on-going process of ICC acquisition. There are three parts (Fig. 1): Language-Culture, the main training process (Input - Notice - Practice Output), and the ICC, which are systematically integrated. The second part is the main part consisting of four teaching steps to facilitate learners' ICC development, and each step reflects a step of the knowledge scaffolding and constructing process to facilitate learners' ICC development.

\section{Language-culture}

This reflects the view of language and culture which is closely intertwined, and it is the foundation for the ICLT model.

Input

This teaching step is aimed at providing learners with language knowledge and intercultural knowledge by exposing learners to a wide range of authentic texts and sources (oral, written, and visual) about language and different cultures. The theory of Krashen's Comprehensible Input Hypothesis (Krashen, 1985) is embedded in this teaching step to increase learners' learning motivation by exposing learners to comprehensible input that is understandable but one step beyond their understanding.

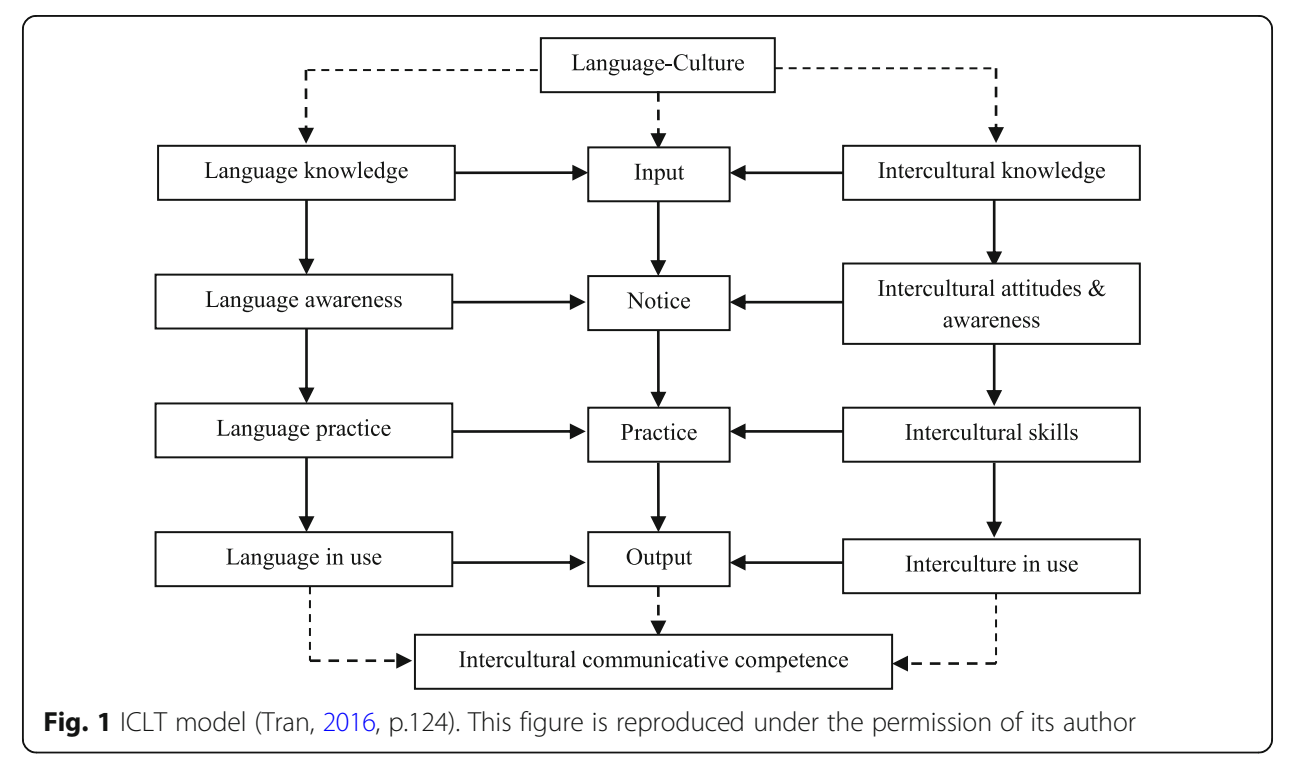




\section{Notice}

Based on their previous knowledge of language and interculture, learners are encouraged to notice and make comparisons between unfamiliar features with known ones. In addition, learners discuss the reasons for language and intercultural features as well as their personal response to those language and intercultural features. This teaching step, which is the next step of the knowledge scaffolding and constructing process, utilizes the theory of Schmidt's Noticing Hypothesis (Schmidt, 1995, 2001) to help to raise learners' language awareness and intercultural awareness and adjust their intercultural attitudes by exposing learners to more authentic learning tasks / activities so that they can attend to and notice unknown features of the input.

\section{Practice}

Learners have a variety of opportunities to practice short, supported and guided communicative tasks about elements of the new knowledge in the two previous teaching steps. Moreover, they have chances to practice using intercultural language strategies for communication in accordance to their language and cultural needs. The theory of Long's Interaction Hypothesis (Long, 1985, 1996) is employed in this teaching step foster learners' ICC development by assisting learners to make use of their previous comprehensible input to enhance their language skills (e.g., speaking, listening, reading, and reading) and intercultural skills (e.g., abilities to interpret the meanings in the target culture and relate them to one's own and to interact with people from different cultures).

\section{Output}

At this stage, learners are able to produce the earlier input features and reflect on their effectiveness and appropriateness. Furthermore, learners are able to explore further in the new language and intercultural features by trying out new forms, expressions, or strategies derived from the earlier input in actual language use through language and intercultural tasks (e.g., project, drama, presentation, etc.). The underlying learning theory is the theory of Swain's Output Hypothesis (Swain, 1995, 2000) which aims to raise learners' awareness of a gap in his/her learning process. This may trigger a new input for another process of the ICLT model as learners' output is a process rather than a product of their ICC learning.

\section{Intercultural communicative competence}

The ultimate goal of ICLT is to help learners to become intercultural speakers with ICC who can interact effectively and appropriately with others from different cultures.

Within this ICLT model, the arrows among the components indicate the sequence of the process, and the dotted arrows depict the interrelationship between the main part and the foundation and the ultimate goal of the ICLT process.

\section{Research setting}

This project was carried out at SouthEast Asian Ministers of Education Organisation, Regional Training Center (SEAMEO RETRAC), a Foreign Language Center in Ho Chi Minh City, Vietnam, which provided a variety of language training programs. Each of which has many levels from elementary to advanced. This center had seventy-seven English language teachers from not only English-speaking countries such as New Zealand, Australia, Canada, the United Kingdom, and the United States of America but also non-English-speaking countries like Vietnam, the Philippines, and South Korea. All these 
teachers held university and/or postgraduate degrees and internationally recognized TESOL qualifications. The Vietnamese teachers of English and foreign teachers of English were scheduled to share the teaching time of each class in accordance to the level of the class.

\section{Course design}

The course lasting over a period of thirteen weeks was instructed by a Vietnamese teacher of English (the researcher), who met the class twice a week, and a foreign teacher of English, who met the class once a week. Each session lasted two hours, so the total number of teaching hours for the whole course was seventy-six including seventy-two in-class teaching hours and four end-of-course assessment hours. As the purpose of this study is to improve the effectiveness of an ICLT model, the intercultural content was included in the English language class. The distribution of teaching hours (Table 1) was that teacher one (the researcher) was responsible for teaching both regular lessons (24 teaching hours) and ICC lessons (24 teaching hours); the foreign teacher was responsible for twenty-four hours of teaching which consisted of language quizzes, IC quizzes and other extra activities; and the last four hours were for language competence (LC) tests and IC tests administered by external teachers other than the teachers who were responsible for teaching the class.

\section{Participants}

The participants were forty-seven EFL learners from three elementary classes who were learning General English at SEAMEO RETRAC in Ho Chi Minh City, Vietnam. As can be seen from Table 2, there was Just over half (53.2\%) of the participants were aged under 20 , i.e., the participants were quite young. Additionally, around three-fifths (61.6\%) of the participants were university students. That is why nearly seven in ten $(68.1 \%)$ of the participants had other high level qualifications or certificates (e.g., high school baccalaureate) other than bachelor's, master's, or doctoral degrees. Furthermore, a very large majority (78.7\%) of the participants had previously studied English for over five years. Just over a third (34\%) of the participants reported that they had been abroad, and only a very small number (4.3\%) of the participants had taken an intercultural course before. Detailed information on the participants is as follows:

\section{Textbook}

The Four Corners textbook level 2, which is part of Four Corners series by Cambridge University Press (Richards \& Bohlke, 2012), was used in this project. This English textbook is comprised of twelve units, yet for the first stage of the two in the elementary level in the General English program, only six topics from Unit One to Unit Six were

Table 1 Distribution of teaching hours

\begin{tabular}{|c|c|c|c|c|}
\hline \multirow{3}{*}{$\begin{array}{l}\text { Details } \\
\text { Teaching hours }\end{array}$} & \multicolumn{2}{|c|}{ Teacher 1 (Vietnamese) } & \multirow{2}{*}{$\begin{array}{l}\text { Teacher } 2 \\
\text { (Foreigner) }\end{array}$} & \multirow{2}{*}{$\begin{array}{l}\text { External Teachers } \\
\text { (Both) }\end{array}$} \\
\hline & Regular lessons & ICC lessons & & \\
\hline & 24 & 24 & 24 & 4 \\
\hline Teaching components & $\begin{array}{l}\text { - Student book } \\
\text { Four Corners 2A } \\
\text { (Units 1, 3, \& 5) }\end{array}$ & $\begin{array}{l}\text { - Student book } \\
\text { Four Corners 2A } \\
\text { - Additional intercultural } \\
\text { material (Units: } 2,4, \& 6 \text { ) }\end{array}$ & $\begin{array}{l}\text { - Language quizzes } \\
\text { - IC quizzes } \\
\text { - Extra activities }\end{array}$ & $\begin{array}{l}\text { - LC tests } \\
\text { - IC tests }\end{array}$ \\
\hline
\end{tabular}


Table 2 Research participants' general information

\begin{tabular}{|c|c|c|c|}
\hline & & $N=$ & \\
\hline & & $\bar{F}$ & $\%$ \\
\hline Gender & Male & 16 & 34.0 \\
\hline & Female & 31 & 66.0 \\
\hline Age & Under 20 & 25 & 53.2 \\
\hline & $21-30$ & 18 & 38.3 \\
\hline & $31-40$ & 4 & 8.5 \\
\hline & Over 40 & 0 & 0.0 \\
\hline Job & Office worker & 10 & 21.4 \\
\hline & University Student & 29 & 61.6 \\
\hline & School student & 5 & 10.6 \\
\hline & Other & 3 & 6.4 \\
\hline Higher degrees & Bachelor's & 14 & 29.8 \\
\hline & Master's & 1 & 2.1 \\
\hline & Doctorate & 0 & 0.0 \\
\hline & Others & 32 & 68.1 \\
\hline Number of years' learning English & Under 1 & 1 & 2.1 \\
\hline & 1 - under 3 & 1 & 2.1 \\
\hline & $3-5$ & 8 & 17.0 \\
\hline & Over 5 & 37 & 78.7 \\
\hline Have been abroad & Yes & 16 & 34.0 \\
\hline & No & 31 & 66.0 \\
\hline Have taken an intercultural course & Yes & 2 & 4.3 \\
\hline & No & 45 & 95.7 \\
\hline
\end{tabular}

covered. Apart from the core elements in the course syllabus designed by SEAMEO RETRAC, additional intercultural content was integrated into the course. As the purpose of this experiment was to test the effectiveness of the proposed ICLT model, only three intercultural themes (Concept of beauty in different countries for Unit 2, Food and drink in different countries for Unit 4, \& Body language in different countries for Unit 6) were integrated into the language content.

\section{Research instruments}

This project utilized three research instruments: language test, IC test and semistructured group interview in order to collect the data. The language test used to collect data on learners' LC was extracted from the assessment package for Four Corners level 2 by Cambridge University Press (Richards \& Bohlke, 2012). There were two types of test: summative and formative. The former, as an achievement test, included written and oral tests: the written test (76 items) involved listening, reading, grammar, functional languages, and vocabulary; the oral test contained two main activities for pair work. The latter, as a quiz, was also comprised of two tests: written (32 items) and oral tests which were in a similar format of the achievement test. The IC test was utilized to generate data on learners' IC. Akin to the language test, the IC test also included two types of test: summative and formative. The former, as an achievement test, was composed of forty multiple choice items (each of IC elements, namely intercultural 
knowledge, attitudes, awareness, \& skills has 10 items, respectively). The latter, as a quiz, consisted of twenty multiple-choice items (each of IC elements, namely intercultural knowledge, attitudes, awareness, and skills has 5 items, respectively). The semi-structured group interview with three questions was employed to get in-depth information on participants' effectiveness of the ICLT model.

\section{Procedures}

In order to garner data, before the course, summative tests including language test and IC test were administered to forty-seven participants in three classes. During the course, forty-seven participants were required to do the formative tests (both language test and IC test) after three ICC units. After the course, the same forty-seven participants were delivered the same summative tests (language test and IC test). Nevertheless, only fifteen participants (around 32\% of the population) who were chosen based on their willingness for the semi-structured group interview, which was conducted in participants' L1 so that they did not encounter any difficulty in answering interview questions.

With respect to the data analysis, the statistical methods (descriptive statistics: frequency, means, \& standard deviation; inferential statistics: paired-sample $t$-test) were employed to analyze the quantitative analysis generated from the summative and formative tests. Meanwhile, the content analysis was utilized to analyze the qualitative data collected from interviews. Each interviewee was coded with a cardinal number terms of L1, L2, and so on.

So as to increase the validity and reliability, all the research instruments were piloted before the main study. Furthermore, double-coding was employed in order to check and increase the reliability of the content analysis. Two methods for double-coding are intra-coder and inter-coder. For the intra-coding, the researcher chose three pieces of text from the interview items which had been already coded to recode them. The researcher checked the reliability which was set over $65 \%$. Concerning the inter-coding, the researcher had two scholars as inter-coders to recode three pieces of text from the open-ended items. Then, the researcher compared his three coded texts with those from two inter-coders. The two inter-coders and the researcher reached to an agreement level $(83 \%)$ of reliability. As the interview transcriptions were in participants' mother tongue, the researcher had to translate all the transcriptions into English. The researcher then asked one teacher of English to double-check the accuracy of the translated version.

\section{Results}

\section{EFL learners' language competence}

It can be seen from Table 3 that the results from the summative test reveal a significant difference $(t=-10.916 ; p=.000)$ regarding the EFL learners' LC, which denotes that EFL learners' LC improved significantly after the thirteen-week course. With respect to the pre-test score, the average mean score was 5.37 (out of 10), in which the mean score of the pre-written test was 4.82 (out of 10), and that of the pre-oral test was 5.91 (out of 10). Concerning the post-test, it is seen that the average mean score was 8.04 (out of 10), in which the mean scores of the post-written test and the post-oral test were 8.29 and 7.80 (out of 10), respectively. This means that after the course the 
Table 3 EFL learners' LC - Summative test (Paired samples t-test)

\begin{tabular}{|c|c|c|c|c|c|}
\hline \multirow{3}{*}{ 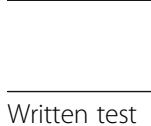 } & \multirow[t]{2}{*}{$\bar{x}$} & \multirow[t]{2}{*}{$t$} & \multirow[t]{2}{*}{ Sig. } & \multicolumn{2}{|c|}{$\bar{X}(S D)(N=47)$} \\
\hline & & & & Pre-test & Post-test \\
\hline & 3.47 & 20.782 & .000 & $4.82(1.01)$ & $8.29(.84)$ \\
\hline Oral test & 1.89 & 18.918 & .000 & $5.91(.66)$ & $7.80(.83)$ \\
\hline Average & 2.67 & 10.916 & .000 & $5.37(.65)$ & $8.04(.59)$ \\
\hline
\end{tabular}

learners' oral score (speaking skills) had generally improved less than their written scores (listening, reading, grammar, functional language, and vocabulary).

Two types of lessons were used in this course: ICC lessons and regular lessons. The former was the one into which IC was integrated, while the latter was the one in which only language content was taught. There was one quiz taken at the end of each unit, so learners had to take six quizzes (formative tests) in total, half of which were taken after three units of ICC. However, for the purpose of this study, only the results of the three quizzes taken after the ICC lessons were included in the analysis.

As shown in Table 4, it is worth pointing out that of the three quizzes, quiz $2(\overline{\mathrm{X}}=8.42)$ had the highest mean score, then quiz $3(\overline{\mathrm{X}}=8.24)$, and quiz $1(\overline{\mathrm{X}}=7.77)$ had the lowest mean score. Similarly, the results of the summative and formative tests show that the mean scores of the written test (quiz 1: $\overline{\mathrm{X}}=8.09$; quiz 2: $\overline{\mathrm{X}}=8.73$; quiz 3: $\overline{\mathrm{XX}}=8.64$ ) were slightly higher than those of the oral test (quiz $1: \bar{X}=7.46$; quiz $2: \bar{X}=8.10$; quiz 3 : $\bar{X}=7.84$ ). Nevertheless, the scores of both the written test and the oral test had a similar pattern of increase.

Furthermore, Table 5 shows that the mean score of quiz 1 was statistically different from that of quiz $2(t=-6.044 ; p=.000)$ and that of quiz $3(t=-4.931 ; p=.000)$, but there was no statistically significant difference in terms of the mean score of quiz 2 and quiz $3(t=1.588 ; p=.119)$. Therefore, learners developed their LC during the intercultural language course. In other words, the learners' language performance improved as a result of the ICC course.

\section{EFL learners' intercultural competence}

Similar to the language test, the IC test also consisted of two types of test: a summative and a formative test. The former was the pre-test and post-test taken at the beginning and at the end of the course, respectively. The latter included three quizzes taken after the units of the ICC lessons. Both the summative and the formative tests each had four main parts, namely knowledge, attitudes, awareness, and skills.

The results from the summative test, as shown in Table 6, indicated that there was a significant improvement in learners' IC $(t=-24.4444 ; p=.000)$ after the thirteen-week

Table 4 EFL learners' LC - Formative test

\begin{tabular}{llll}
\hline Items $(\mathrm{N}=47)$ & Quiz 1 & Quiz 2 & Quiz 3 \\
& $\overline{\mathrm{X}}(\mathrm{SD})$ & $\overline{\mathrm{X}}(\mathrm{SD})$ & $\overline{\mathrm{X}}(\mathrm{SD})$ \\
\hline Written test & $8.09(.91$ & $8.73(.86)$ & $8.64(1.12)$ \\
Oral test & $7.46(.79)$ & $8.10(.77)$ & $7.84(.83)$ \\
Average & $7.77(.53)$ & $8.42(.58)$ & $8.24(.69)$ \\
\hline
\end{tabular}


Table 5 EFL learners' LC - Formative test (Paired differences- Paired samples t-test)

\begin{tabular}{lllll}
\hline & & $\bar{X}$ & $t$ & Sig. \\
\hline Pair 1 & Quiz 1 - Quiz 2 & -.65 & -6.044 & .000 \\
Pair 2 & Quiz 1 - Quiz 3 & -.47 & -4.931 & .000 \\
Pair 3 & Quiz 2 - Quiz 3 & .18 & -1.588 & .119 \\
\hline$p \leq .05$ & & &
\end{tabular}

course. In particular, it is worth pointing out that the pre-test mean score was nearly at an average level $(\overline{\mathrm{X}}=4.72$ out of 10$)$ although a very large majority $(95.7 \%$; see section 4.2) of the learners reported that they had never taken any intercultural course before. Moreover, it was found that at the beginning of the course the four components of IC, namely, intercultural skills $(\bar{X}=4.85)$, intercultural attitudes $(\bar{X}=4.79)$, intercultural awareness $(\overline{\mathrm{X}}=4.64)$, and intercultural knowledge $(\overline{\mathrm{X}}=4.60)$ were in descending order; yet, after the course, learners got the highest score in intercultural knowledge $(\overline{\mathrm{X}}=7.91)$, followed by the intercultural skills $(\overline{\mathrm{X}}=7.77)$, intercultural attitudes $(\overline{\mathrm{X}}=7.66)$, and intercultural awareness $(\overline{\mathrm{X}}=7.45)$. Overall, learners made a significant improvement in IC over the thirteen-week course, but their intercultural knowledge was the most component that improved most $(\overline{\mathrm{X}}=3.31)$, while their intercultural awareness improved least $(\overline{\mathrm{X}}=2.81)$.

Turning to the results from the formative tests (Table 7), it can be in particular that there was a slight improvement in participants' IC (quiz 1: $\overline{\mathrm{X}}=7.00$; quiz 2: $\overline{\mathrm{X}}=7.35$; quiz 3: $\bar{X}=7.19$ out of 10$)$. Similar to the summative tests, knowledge was the most significantly improved component (quiz 1 : $\overline{\mathrm{X}}=7.48$; quiz 2 : $\overline{\mathrm{X}}=7.74$; quiz 3 : $\overline{\mathrm{X}}=7.58$ ) of the four IC components, and awareness was the least improved (quiz 1: $\bar{X}=6.24$; quiz 2: $\overline{\mathrm{X}}=6.72$; quiz 3: $\overline{\mathrm{X}}=6.68$ ). Additionally, all four IC components had the same pattern of improvement through the three quizzes, i.e., the result of quiz 1 was the lowest and quiz 2 had the highest result. These results reveal that learners found intercultural knowledge and skills easier to improve than intercultural attitudes and awareness.

The results in Table 8 indicate that there was no statistically significant difference in respect of the mean scores of the two paired quizzes: quiz 1 and quiz $3(t=-1.282$; $p=.206)$; quiz 2 and quiz $3(t=.898 ; p=.374)$, but the mean score of quiz 1 was statistically different from that of quiz $2(t=-2.018 ; p=.049)$. This means that learners' IC development was relatively steady during the intercultural language course.

When LC and IC were combined for further analysis, it was noticed that both LC and IC had a similar pattern of increase over a period of three months. At the beginning of the course, the pre-test results (both IC and LC) were relatively high in

Table 6 EFL learners' IC - Pre-test and Post-test (Paired samples t-test)

\begin{tabular}{llllll}
\hline & $\bar{X}$ & $\mathrm{t}$ & $\mathrm{Sig}$ & & $\bar{X}(\mathrm{SD})(N=47)$ \\
\cline { 5 - 6 } & & & & Pre-test & Post-test \\
\hline Knowledge & 3.31 & 16.432 & .000 & $4.60(.74)$ & $7.91(.43)$ \\
Attitudes & 2.87 & 13.544 & .000 & $4.79(.86)$ & $7.66(1.12)$ \\
Awareness & 2.81 & 14.667 & .000 & $4.64(.82)$ & $7.45(.94)$ \\
Skills & 2.92 & 16.477 & .000 & $4.85(.88)$ & $7.77(1.00)$ \\
Average & 2.98 & 22.946 & .000 & $4.72(.43)$ & $7.70(.74)$ \\
\hline$p \leq .05$ & & & & &
\end{tabular}


Table 7 EFL learners' IC - Formative test

\begin{tabular}{llll}
\hline Items $(N=47)$ & Quiz 1 & Quiz 2 & Quiz 3 \\
& $\bar{X}(S D)$ & $\bar{X}(S D)$ & $\bar{X}(S D)$ \\
\hline Knowledge & $7.48(1.03)$ & $7.74(.90)$ & $7.58(.75)$ \\
Attitudes & $6.98(.66)$ & $7.40(.86)$ & $7.24(.53)$ \\
Awareness & $6.24(.78)$ & $6.72(.67)$ & $6.68(.67)$ \\
Skills & $7.14(.68)$ & $7.53(.76)$ & $7.24(.61)$ \\
Average & $7.00(.69)$ & $7.35(.90)$ & $7.19(.81)$ \\
\hline
\end{tabular}

comparison to the required level for the course. After the three-month course, as shown in Fig. 2, the learners' level of ICC had improved despite the limited number of hours of study for intercultural language. It can be further seen that there was a rapid increase in terms of the mean scores (both IC and LC) between the pre-test and quiz 1, and then there was a gradual development in learners' ICC towards the end of the course.

In order to triangulate the findings as well as to obtain in-depth information from the quantitative data analysis, the qualitative data from the interview were also taken into account. The findings reveal that the EFL learners' ICC gradually changed positively over the course.

A number of interviewees (26.7\%) confided that although they had spent years on learning English before, their English was not really at a high level due to their dislike of this subject in high school. When they took this course, albeit their IC markedly improved, they felt that their English had not improved much. However, their improvement in English met the level required by the course objectives.

In this course, I liked learning about other cultures, and it helps to me learn English as well as other cultures although my English is improved a little, but I know more about English and other cultures (L3).

When I was at high school, I did not want to study English much. Therefore, I was not really good at English. Now my English is still weak, but I can feel my English is improved, especially my knowledge of different cultures (L7).

Some (20\%) also said that their IC improved more than their LC because they paid more attention to the cultural content while studying on the course.

I prefer cultural content to English, so I know more about cultures. My English is developed a little (L4).

Table 8 EFL learners' IC - Formative test (Paired differences- Paired samples t-test)

\begin{tabular}{lllll}
\hline & & $\bar{X}$ & $t$ & Sig. \\
\hline Pair 1 & Quiz 1 - Quiz 2 & -.35 & -2.018 & .049 \\
Pair 2 & Quiz 1 - Quiz 3 & -.19 & -1.282 & .206 \\
Pair 3 & Quiz 2 - Quiz 3 & .16 & .898 & .374 \\
\hline$p \leq .05$ & & &
\end{tabular}




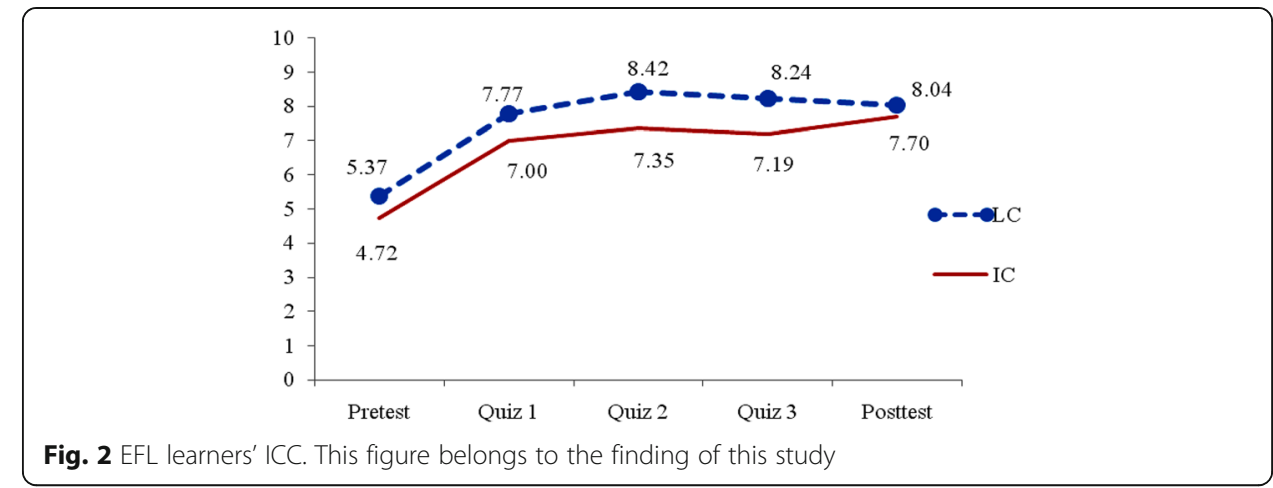

Further to this, one interviewee commented that when at high school, she was unaware whether it was necessary to learn cultures when learning English. Nor was she in favor of learning English. Nevertheless, when she came on this course, she realized that it helped to change her attitudes toward learning English as well as to improve her ICC.

I used to learn English in order to pass English exams, so I did not pay attention much to language skills. Besides, I did not care whether I should learn cultures when learning English or not. However, during this course I realized that it was interesting to learn cultures through learning English. Consequently, I feel that my ICC is improved quite a lot (L5).

Meanwhile, many others (40\%) confirmed that they had developed both their LC and IC over the course. Moreover, they expressed their hope that they would be able to have similar courses in the future as they thought that using English appropriately was important for their jobs. Just one of many examples is as follows:

After this course, my English is better and I know more about other cultures. I hope that there will be more similar courses because it is very important for me to know and use English in an appropriate way. English is important for my job (L14).

Regarding the specific elements of IC, a considerable number (73.3\%) of those interviewed reported that their intercultural knowledge improved a lot. Two of them said:

I know different things about concepts of beauty, foods and drinks and body languages of different cultures (L7).

...my understanding other cultures is better as I know more about other cultures and my own (L15).

They additionally commented that their intercultural attitudes and awareness were positively changed. One shared:

...my attitudes toward other cultures have been adjusted because I understand more about other cultures, especially cultural difference (L11). 
Their intercultural skills were also remarkably developed. They reported that they knew how to avoid cultural misunderstanding and conflict as they had learned different strategies for IC and knew how to use English more effectively and appropriately in intercultural situations.

...I know how to use appropriate English in different situations...I know how to avoid cultural misunderstanding (L5).

...I know how to communicate well when I meet them. I know how to avoid conflict or at least I know some strategies when talking to foreigners when I first meet them (L8).

...I know how to use English effectively and appropriately in intercultural situations.

I know different strategies for IC (L9).

On the other hand, it was noticeable that quite a small number $(13.3 \%)$ of those interviewed stated that although this type of course was of interest, they would have preferred to learn English rather than culture since their English language skills were still weak. They wanted to focus more on their grammar, and that is why their IC had not improved much. The most obvious example of this view is:

To me, it is very interesting to learn both culture and English in English lessons, but I don't want to spend much time on learning different cultures because my English is not very good. I want to improve my English grammar and skills. Therefore, after this course I do not feel much improvement in my IC (L10).

\section{Discussion}

The results from the LC summative tests reveal that there was a significant improvement in EFL learners' LC after the thirteen-week ICC course. This means that the learners were able to improve their LC while learning intercultural content. It is likely that learners were aware of the important roles of English language and English language learning in the context of globalization. Furthermore, learners in this study were those who had a strong will to improve their English language proficiency because they took the English training course by choice as an extra course at a language center.

Specifically, it was seen that learners' oral scores (speaking skill) did not improve as much as their written scores (listening, reading, grammar, functional languages, and vocabulary) by the end of the course. Nonetheless, the results also show that learners' speaking skills at the beginning of the course were relatively good in comparison with the required level for the course. It may be understood from this that learners' speaking skills which were at a high level did not develop much after the course because it takes a long time for learners to improve their speaking skills. Also, some learners find speaking skills the most difficult to be develop as pointed by many scholars (e.g., Pawlak, Waniek-Klimczak, \& Majer, 2011; Waniek-Klimczak \& Klimczak, 2008). It is generally 
agreed that speaking skills are the most difficult to improve of the four macro skills (listening, speaking, reading, and writing).

As for the results from the LC formative tests (quizzes) obtained after the ICC lessons, it was found that learners' LC progressed gradually during the course, albeit the learners' pre-test scores $(\overline{\mathrm{X}}=5.37)$ were at a high starting point. Yet, the results from the three LC quizzes showed that progress fluctuated in terms of the mean scores (quiz 1: $\overline{\mathrm{X}}=7.77$; quiz 2: $\overline{\mathrm{X}}=8.42$; quiz $3: \overline{\mathrm{X}}=8.24$ ), and there was a similar pattern of increase in both the oral and written tests of the three LC formative tests. Furthermore, there were differences in terms of mean scores between quiz 1 and quiz 2; quiz 1 and 3, but there was no difference in terms of mean scores between quiz 2 and quiz 3. This indicates a considerable improvement in learners' LC at different times: from quiz 1 to quiz 2, and from quiz 1 to quiz 3. Possibly, the degree of difficulty of three quizzes was different from one another, although the test items in each quiz reflected the language content of each unit.

The quantitative findings from the IC summative tests indicated that learners' IC improved significantly, i.e., the ICC training course helped learners to improve their IC after three months. One of the possible explanations is that learners had positive perceptions of ICLT, so they were motivated to learn the intercultural content through learning the language content. Furthermore, learners were aware that IC is becoming part of the necessary professional skills required for future jobs, and they understood that IC had the "capacity to change one's knowledge, attitudes and behaviors so as to be open and flexible to other cultures has become a critical issue for individuals to survive in the globalized society of the twenty-first century" (Davis, 2005, p. 4). As a result, they became more aware of their learning needs during the course.

With respect to the IC formative tests (quizzes), the findings indicated that learners developed relatively gradually. The mean scores of the three IC quizzes fluctuated slightly (quiz 1 : $\overline{\mathrm{X}}=7.00$; quiz $2: \overline{\mathrm{X}}=7.35$; quiz $3: \overline{\mathrm{X}}=7.19$ ), and there was only a difference in terms of the mean scores between quiz 1 and quiz 2. The reason for this may be due to the degree of difficulty of each quiz. As three intercultural themes (Concept of Beauty in different countries for Unit 2, Food and Drink in different countries for Unit 4, and Body Language in different countries for Unit 6) were integrated into the English language units, the intercultural themes for Units 1 and 3 were quite abstract and new to learners while the theme for Unit 2 was visual and more familiar to the learners. The four IC components (intercultural knowledge, attitudes, awareness, \& skills) developed significantly in a similar pattern. Nevertheless, the order of improvement of learners' IC components was intercultural knowledge, skills, attitudes, and awareness. This means that the most significantly improved IC component was intercultural knowledge whilst the least significantly improved was intercultural awareness. This may be that intercultural knowledge is easier to acquire than the other IC components. Therefore, learners developed their intercultural knowledge most and their intercultural awareness least.

The findings from the qualitative data analysis showed that learners developed their ICC (both LC and IC) significantly. In addition, learners were motivated to study on this intercultural language course, so that they could expand their worldviews. These results match those of previous studies (e.g., O’Neil, 2008; Shoman, 2011; Gómez, 2012; Ottoson, 2013). A representative example of this is that Shoman (2011) conducted a 
study using a framework to develop ICC and the proficiency of advanced learners of Arabic. The findings revealed that the proposed linguacultural framework not only developed learners' abilities to recognize as well as produce Arabic varieties used in Egypt but also fostered their IC abilities (knowledge, attitude, awareness, \& skills). In another context, O'Neil (2008) conducted research on fostering learners' IC by implementing an interactional virtual elementary classroom, and found that learners developed their LC, specifically their writing skills through the course, and that there were positive changes in learners' IC. Therefore, the ICC training course not only improved learners' LC, but also developed their IC significantly.

Notwithstanding, it was also revealed that some learners who developed their ICC, also improved their IC more than their LC and vice versa. It may be the case that these learners focused more on either LC or IC of ICC during the ICC training course. For those whose LC improved the most, although their English language proficiency was still weak, they thought that it was more important to improve their LC than their IC. On the contrary, for those whose IC was more developed, intercultural learning was new to them as most (95.7\%) of the learners had never taken an intercultural course before, and they were more interested in IC because of its important role in communication. Consequently, their LC and IC were not developed simultaneously at a similarly high level.

\section{Conclusion}

The study showed that the ICLT model was seen an effective form of intercultural language education to facilitate the achievement of learners' ICC (both LC and IC). Generally, both the learners' LC and IC developed in a similar pattern, which indicates that learners can learn intercultural content through language content and vice versa. This study might suggest that in a long term the ICLT model can equip learners with ICC in order to become intercultural speakers who can be fluent in a foreign language and function appropriately and effectively in the context of globalization. However, in order to make the ICLT happen in the Vietnamese context, there should be radical changes in teaching methodology which shifts its current approach to intercultural language approach. The ICLT model should be experimented at various educational levels in different contexts in order to further confirm the effectiveness of this model. Additionally, different supportive factors on learners' ICC development should be scrutinized so as to facilitate the process of learners' intercultural language learning.

\footnotetext{
Abbreviations

EFL: English as a foreign language; ESL: English as a second language; IC: Intercultural competence; ICC: Intercultural communicative competence; ICLT: Intercultural communicative language teaching; LC: Language competence; SEAMEO RETRAC: SouthEast Asian Ministers of Education Organisation, Regional Training Center; TESOL: Teaching English to speakers of other languages
} in this study, reviewing experts for their constructive suggestions as well as comments, and the Board of directors of SEAMEO RETRAC for their consent to conduct the experiment at their language center. Without their willingness, help, and support, this project would never have been completed. 


\section{Competing interests}

The authors declare that they have no competing interests.

\section{Publisher's Note}

Springer Nature remains neutral with regard to jurisdictional claims in published maps and institutional affiliations.

\section{Author details}

${ }^{1}$ Faculty of English Language, Ho Chi Minh City University of Technology, 475A Dien Bien Phu Street, Ward 25, Binh Thanh District, Ho Chi Minh City 700000, Vietnam. ${ }^{2}$ Faculty of Foreign Languages, Nong Lam University, Vietnam, Linh Trung Ward, Thu Duc district, Ho Chi Minh City 700000, Vietnam.

Received: 12 December 2017 Accepted: 19 April 2018

Published online: 25 April 2018

\section{References}

Alexandru, F. (2012). The context for developing intercultural communicative competence. Euromentor Journal, 3(1), 35-53. Bennett, J. M., \& Bennett, M. J. (2004). Developing intercultural sensitivity. In J. M. Bennett, M. J. Bennett, \& D. Landis (Eds.), Handbook of intercultural training (3rd ed., pp. 147-165). Thousand Oaks, CA: Sage Publications.

Byram, M. (1997). Teaching and assessing intercultural communicative competence. Philadelphia, PA: Multilingual Matters.

Davis, N. (2005). Intercultural competence for future leaders of educational technology and its evaluation. Interactive Educational Multimedia, 10, 1-22.

Deardorff, D. K. (2006). Identification and assessment of intercultural competence as student outcome of internationalization. Journal of Studies in Intercultural Education, 10, 241-266.

Deardorff, D. K. (Ed.). (2009). The SAGE handbook of intercultural competence. Thousand Oaks, CA: Sage Publications.

Fantini, A. (1997). New ways in teaching culture. Alexandria, VA: TESOL Inc.

Fantini, A. (2001). Exploring intercultural competence: A construct proposal. Paper presented at the 4th annual conference of NCOLCTL Fourth Annual Conference, April 2001, Las Vegas, USA.

Fantini, A. E. (2000). A Central Concern: Developing Intercultural Competence. SIT Occasional Papers Series: Addressing Intercultural Education, Training and Service, 1, 25-42.

Garretts-Rucks, P. (2010). The Emergence of U.S. French Language Learners' Intercultural Competence in Online Classroom Discussions. In Doctoral dissertation. USA: University of Wisconsin-Madison.

Gómez, R. L. F. (2012). Fostering intercultural communicative competence through reading authentic literary texts in an advanced Colombian EFL classroom: A constructivist perspective. Profile Issues in Teachers' Professional Development 14(1), 49-66 Retrieved from http://www.redalyc.org/articulo.oa?id=169224317004.

Gonen, S. I. K., \& Saglam, S. (2012). Teaching culture in the FL classroom: Teachers' perspectives. IJGE: International Journal of Global Education, 1(3), 26-46.

Hong, S. (2008). The role of heritage students in incorporating culture into language teaching. South Asia Language Pedagogy and Technology, 1. Retrieved from https://apps.cla.umn.edu/directory/items/publication/316719.pdf.

Jæger, K. (2001). The intercultural speaker and present-day requirements regarding linguistic and cultural competence. Sprogforum, 19, 52-56.

Krashen, S. (1985). The input hypothesis. New York: Longman.

Lázár, l., Huber-Kriegler, M., Lussier, D., Matei, G. S., \& Peck, C. (Eds.). (2007). Developing and Assessing Intercultural Communicative Competence - A Guide for Language Teachers and Teacher Educators, European Centre for Modern Languages. Strasbourg: Council of Europe.

Long, M. H. (1985). Input and second language acquisition theory. In S. M. Gass \& C. G. Madden (Eds.), Input in second language acquisition (pp. 377-393). Rowley, MA: Newbury House.

Long, M. H. (1996). The role of the linguistic environment in second language acquisition. In W. C. Ritchie \& T. K. Bhatia (Eds.), Handbook of second language acquisition (pp. 413-468). New York: Academic Press.

Moloney, A. R. (2007). Intercultural Competence in Young Language Learners: A Case Study. In Doctoral dissertation. Australia: University of Sydney.

Nakano, Y., Fukui, S., Nuspliger, B., \& Gilbert, J. (2011). Developing intercultural communicative competence through guest speaker sessions - two case studies. Human Welfare, 3(1), 23-52.

Onalan, O. (2005). EFL teachers' perceptions of the place of culture in ELT: A survey at four universities in Ankara/ Turkey. Journal of Language and Linguistic Studies, 1(2),215-235.

O'Neil, J. E. (2008). Intercultural Competence Development: Implementing International Virtual Elementary Classroom Activities into Public Schools in the U.S. and Korea. In Doctoral dissertation. Virginia, USA: University of Virginia.

Ottoson, K. J. (2013). Classroom development of intercultural competence. In N. Sonda \& A. Krause (Eds.), JALT1 conference proceedings. Tokyo: JALT.

Pawlak, M., Waniek-Klimczak, E., \& Majer, J. (2011). Speaking and instructed foreign language acquisition. Bristol: Multilingual Matters.

Pierson, R. (2010). Intercultural Competence and Study Abroad in a Language-Neutral Environment: An Analysis of Undergraduates at Arcadia University. Doctoral dissertation. USA: Capella University.

Richards, J. C., \& Bohlke, D. (2012). Four corners series. Cambridge: Cambridge University Press.

Samovar, L. A., Porter, R. E., \& McDaniel, E. R. (2012). Intercultural communication: A reader (13th ed.). Boston: Wadsworth Cengage Learning.

Schmidt, R. (1995). Consciousness and foreign language learning: A tutorial on the role of attention and awareness in learning. In R. Schmidt (Ed.), Attention and awareness in foreign language learning (pp. 1-63). Honolulu, HI: University of Hawaii, Second Language Teaching \& Curriculum Center.

Schmidt, R. (2001). Attention. In P. Robinson (Ed.), Cognition and second lanquage instruction (pp. 3-32). Cambridge: Cambridge University Press. 
Sercu, L. (2005). Teaching foreign languages in an intercultural world. In M. Byram \& A. Phipps (Eds.), Foreign language teachers and intercultural competence (pp. 1-18). Buffalo: Multilingual Matters, Ltd..

Shoman, M. M. (2011). Developing Intercultural Communicative Competence and Proficiency of Advanced Arabic Learners: A Proposed Framework. Master thesis. Cairo: The American University.

Sinicrope, C., Norris, J., \& Watanabe, Y. (2007). Understanding and assessing intercultural competence: A summary of theory, research, and practice (technical report for the foreign language program evaluation project). Second Language Studies, 26(1), 1-58.

Swain, M. (1995). Three functions of output in second language learning. In G. Cook \& B. Seidlhofer (Eds.), Principle and practice in applied linguistics: Studies in honour of H. G. Widdowson (pp. 125-144). Oxford: Oxford University Press.

Swain, M. (2000). The output hypothesis and beyond: Mediating acquisition through collaborative dialogue. In J. P. Lantolf (Ed.), sociocultural theory and second Language Learning (pp. 97-114). Oxford: Oxford University Press.

Tavakoli, M., Shirinbakhsh, S., \& Rezazadeh, M. (2012). The Effect of Cultural Adaptation on EFL Reading Comprehension: The Role of Narrative Nativization and Foreign Language Attitude. 3L: The Southeast Asian Journal of English Language Studies, 18(4), 145-157.

Tran, T. Q. (2016). An Intercultural Communicative Language Teaching for EFL Learners. In Doctoral dissertation. Nakhon Ratchasima: Suranaree University of Technology.

Waniek-Klimczak, E., \& Klimczak, K. (2008). Target in Speech Development: Learners' Views. In K. Dziubalska-Kołaczyk \& J. Przedlacka (Eds.), English Pronunciation Models: A Changing Scene (pp. 229-249). Bern: Peter Lang.

\section{Submit your manuscript to a SpringerOpen ${ }^{\circ}$ journal and benefit from:}

- Convenient online submission

- Rigorous peer review

- Open access: articles freely available online

- High visibility within the field

- Retaining the copyright to your article

Submit your next manuscript at $>$ springeropen.com 